Um filme é toda nossa vida: resenha de A metafísica da cinefilia (2021), de Yves São Paulo

\author{
Hanna Cláudia Freitas Rodrigues ${ }^{1}$
}

\footnotetext{
${ }^{1}$ Hanna Cláudia Freitas Rodrigues: Doutoranda em Artes da Cena pelo Programa de Pós-graduação em Artes da Cena da Escola de Comunicação da Universidade Federal do Rio de Janeiro (UFRJ), mestre em Comunicação, Arte e Memória - Mídia e Formatos Narrativos, pela Universidade Federal do Recôncavo da Bahia (UFRB). Especialista em Filosofia Contemporânea pela Universidade Estadual de Feira de Santana (UEFS) e integrante pelo CNPq do Núcleo Interdisciplinar de Estudo e Pesquisa em Filosofia (NEF) da Universidade Estadual de Feira de Santana (UEFS). Possui Graduação em Direito pela Faculdade Social da Bahia (FSBA) e é pesquisadora associada do Instituto Brasileiro de Direito Urbanístico (IBDU). Membra pela CAPES do Grupo de Estudos em Corpo na Filosofia e Psicanálise (GEFIP), coordenado pela Prof. ${ }^{a}$ Dr. ${ }^{\text {a }}$ Caroline Vasconcelos (UEFS); do Grupo de Estudos em Ciência Política: "Nenhuma rede é maior do que o mar: rede de sentidos, antagonismo e ontologia", coordenado pelo Prof. Dr. Laurênio Leite Sombra (UEFS); do Grupo de Pesquisa Territorialidade, Direito e Insurgência, coordenado pela prof. Dra Adriana Nogueira Vieira Lima (UEFS), do Grupo de Pesquisa, Estudo e Extensão em Artes, Audiovisual e Patrimônio (GAAP), coordenado pelo Prof. Dr. Danillo Barata (UFRB); e, do Grupo de Pesquisa Corpo e Cultura, coordenado pela Prof. ${ }^{a}$ Dr. ${ }^{\text {a }}$ Renata Pitombo (UFRB). Compõe equipe editorial da Revista Sísifo (ISSN: 2359-3121). Professora no Centro Universitário de Cultura e Arte (CUCA), da Universidade Estadual de Feira de Santana (UEFS). Possui formação profissional em Linguagens do Movimento, pela Escola Contemporânea de Dança da Bahia (Dirigida por Fátima Suarez); Artista visual e do corpo, bailarina profissional e performer urbano-intervencionista. Email: hannacfr@gmail.com
} 
Parece lugar-comum afirmar que a cinefilia é uma paixão, sendo, portanto, uma emoção. Apesar desta obviedade para a sapiência popular, impressiona ao acadêmico descobrir que o espaço dado à cinefilia nos estudos teóricos, pouco se aproxima desta concepção, mantendo-a como um aspecto marginal, pouco procurando desenvolver de fato o que seria uma emoção tão particular quanto a cinefilia, nascida a partir da invenção de um dispositivo tecnológico. Os estudos mais famosos envolvendo a cinefilia - como o de Antoine de Baecque (2010) - compreendem o fenômeno sociocultural da ida às salas de cinema, e a crítica surgida da assiduidade destas visitas. Uma perspectiva que lança a cinefilia como uma paixão restrita, permitida apenas aos habitantes de grandes metrópoles onde a grande variedade de salas de cinema também significa grande variedade em títulos de filmes sendo exibidos. Indo de encontro a esta narrativa, Yves São Paulo retoma o lugar-comum da concepção de cinefilia para desenvolver um livro por vezes difícil em seu vocabulário academicista, de linguagem sofisticada, explorando filosoficamente a cinefilia como emoção.

Em A metafísica da cinefilia (2021), Yves São Paulo parte do pressuposto de que o espectador aborda o filme munido com um arsenal de experiências e ideias que 0 fazem colocar a obra em perspectiva. Para além disso, uma parte desta base de relação com o filme compreende a algo de ainda mais elementar, apresentado desde o princípio pelo título enigmático da obra, a metafísica. Aqui entra em ação também o subtítulo do livro, uma leitura bergsoniana do cinema, apontando o caminho do sentido de metafísica que será tratado ao longo do livro.

Parece ser o intuito de Yves São Paulo nesta obra, buscar o que há de fundamental, tanto no espectador quanto no filme, que permita a comunhão entre ambos. Esta fundamentação encontra-se a um campo metafísico, mas como a argumentação nos mostrará, isso não significa um fora, ou uma anterioridade, à experiência. Trata-se de algo que se encontra enraizado em toda experiência. Eis a opção pela filosofia de Henri Bergson para guiar este livro, a metafísica não compreende a algo anterior à experiência nem algo de externo à experiência porque nem um nem outro poderiam ser de fato conhecidos, apenas especulados.

O livro acompanha a divisão metodológica feita pelo próprio Bergson no ensaio Introdução à metafísica (1966). A Parte Um se ocupa com o que São Paulo chama de "análise", um modelo que no cinema se traduz por meio do corte acelerado, sintético e significante - em conjunto com o conteúdo das imagens, igualmente direto - de modo que a ação do espectador analítico seja recortar o filme, criando símbolos externos a partir daquilo que lhe é oferecido. A Parte Dois aborda o método encontrado pelo filósofo francês para se alcançar uma experiência imediata com a duração. Diferente do que acontece com a abordagem analítica, a abordagem intuitiva compreende a filmes que 
não oferecem dados para síntese significativa, levando o espectador a mergulhar na experiência do filme, não tentando posicionar-se de fora, mas dentro dele, fazendo com que cada parte da obra se inscreva em seu tecido de memória.

Assim se revela a Parte Três do livro, realizando o casamento entre as duas partes anteriores que se poderia pensar serem irreconciliáveis. Contudo, São Paulo aponta para o fato de que dificilmente o espectador consegue encarar um filme com apenas uma das abordagens descritas - assim como não deliberadamente escolhe uma à outra. Uma mistura entre as duas desenvolve o que o autor chama de "criação por arte do espectador", quando criamos um filme que é todo próprio, nosso, moldado pela nossa experiência. Deste ato criativo, surge a cinefilia.

Algumas das passagens mais bonitas do livro estão guardadas nesta Parte Três, quando Yves São Paulo começa a descrever a cinefilia enquanto paixão e o seu impacto sobre a vida de quem vem a sentir esta emoção. Escreve ele:

Aqui nasce a cinefilia enquanto emoção, quando a ação do espectador em sua relação com o filme faz com que a obra se inscreva profundamente em sua consciência, em seu espírito, levando a manter guardado aquele filme, com suas ideias, seus sentimentos, seus detalhes, toda a riqueza que uma película é capaz de despertar em quem assiste. (SÃO PAULO, 2021: 205)

Muitas vezes a descrição da cinefilia se aproximará da descrição da abordagem intuitiva, igualmente carreada por um sentimento poético de enxergar a realidade sem mediação. Não estranha que São Paulo relembre que Bergson trata a intuição como sendo o método dos artistas, eles mesmos experimentando a realidade em sua imediatez. A experiência da cinefilia faz com que o filme arrebate o Todo de nosso ser, aqui chamado pelo autor de "Absoluto", numa reunião do passado do espectador com o presente e o porvir durante a exibição de um filme. Assim, lê-se:

O Absoluto enraíza a duração do filme em nosso espírito, penetrando em nossas lembranças e fixando da forma mais consistente que encontra esta experiência em nosso fluxo de vida; o filme começa a dialogar não somente com o eu presente, nem somente com a memória imediata ou mais à superfície, o Absoluto passa a fazer relação com toda a nossa vida e transforma a experiência do filme em mais do que um certo momento de lazer: assistir filme se transforma numa espécie de necessidade vital. O filme não faz parte apenas do momento presente, é toda nossa vida, é 
experiência que nos leva a viver uma vida maior que a própria vida. (São Paulo, 2021: 224-225)

Auxiliando a noção de fazer parte da experiência cotidiana, não deixando o vocabulário filosófico utilizado parecer demasiado abstrato ao leitor, Yves São Paulo insere alguns debates a respeito da influência social sobre o arsenal prévio que caracteriza a experiência do espectador, mostrando também a influência de noções da metafísica sobre tais procedimentos. Surge particularmente interessante 0 desenvolvimento acerca da metafísica do tempo espacializado e sua influência sobre a indústria, o que eventualmente marcará a abordagem do espectador analítico. Raras foram as vezes em que pudemos ter em mãos uma interpretação crítica do Taylorismo à luz da metafísica da duração de Bergson, lançando frutos para uma teoria do espectador de cinema. Esta aproximação é feita levando em conta que os três fenômenos mencionados - Taylorismo, o surgimento da filosofia de Bergson, o nascimento do cinema - acontecem em concomitância num período muito particular da história.

Parece que estamos a ler a respeito de Benjamin - uma lembrança feita pelo professor Claudio Novaes no prefácio ao livro - pensando a modernidade via Baudelaire, e de certa maneira esta influência se apresenta de modo sutil por meio da leitura de Mary Ann Doane, uma das principais referências trabalhadas por São Paulo, especialmente no contexto da Parte Um. A modernidade que acelera o movimento dos transeuntes da urbe é a mesma que acelera o movimento dentro dos filmes, acelera os cortes, faz com que o tempo de cada plano fique mais curto, exigindo uma mudança de abordagem por parte do espectador, também ele cada vez mais impaciente.

Os exemplos de filmes dados na parte sobre a analítica diferem daqueles da parte sobre a intuição, especialmente ao levar o ritmo da montagem em consideração. A ideia lançada aqui é de que a analítica abraça um ritmo acelerado da montagem, enquanto a intuição abriga o ritmo mais cauteloso. Contudo, o que acontece é que estes dois polos são parte de uma dialética, não existindo um sem a participação do outro. Não existe arte sem técnica, não existe conceito sem que antes venha inspiração.

A dialética entre análise e intuição abre espaço para que se quebre uma velha e comum associação feita quando considerando o espectador: a sua passividade. Esta dialética abre caminho para uma releitura da famosa teoria da liberdade bergsoniana que influenciou, entre outras, a sartreana - para apresentar um espectador que mesmo restrito ao espaço de sua cadeira é um criador. A liberdade do porvir fílmico encaminha o espectador em direção a uma construção intelectual do filme e de si mesmo, numa comunhão tão que em seu grau mais aprofundado cria o sentimento de cinefilia, esta 
singularidade onde já não distinguimos o cinema - e seus particulares, os filmes - como algo dissociado de nosso ser. O cinéfilo assiste filmes por que precisa.

A metafísica da cinefilia proposta por São Paulo pode ser resumida na busca pela característica comum que une filme e espectador, rompendo mais uma noção comumente feita quando pensamos a relação de espectador: não se trata de uma relação sujeito (espectador) objeto (filme), sendo antes a progressão contínua de um a outro. Ou seja, na metafísica da cinefilia a duração possui caráter central ao ser o que é capaz de unir filme e espectador num mesmo tecido de memória. Portanto, não existe aqui sujeito nem objeto, mas uma progressão de um Absoluto durável em direção de outro. O espectador não é receptáculo, nem o filme se encontra privado de ganhar com a experiência do espectador.

Ao leitor da Metafísica da cinefilia fica um pouco de curiosidade e desejo de que seu autor trate mais prolongadamente a respeito da experiência coletiva de assistir a um filme, quando reações da plateia interferem diretamente nesse jogo entre Absolutos, envolvendo mais uma parte à equação. Fora isso, é refrescante encontrar um texto como este buscando o tratamento filosófico do cinema no cenário acadêmico brasileiro, mais entregue ao ensaio de teorizar - pesadamente a partir de Bergson - do que de aplicar conceitos filosóficos clássicos a análises de filmes.

\section{Referencia Bibliográfica:}

SÃo PAULO, Yves. Metafísica da Cinefilia: uma leitura Bergsoniana do Cinema. Clube de Autores, 2021.

Submetido em 18 de maio de 2021 / Aceito em 15 de junho de 2021. 